TILD-LIFE PHOTOGRAPHY IN AMERICA. THE greater part of the June issue of the National Geographic Magazine is occupied by a lavishly illustrated article by the Hon. E. Shiras (who claims, we believe, to be the pioneer in flashlight photography) entitled "One Season's Game-bag with the Camera." The author is convinced that photographing big game in their native wilds is in a fair way to supersede shooting them, although we are fain to confess that so far as this country is concerned we fail to see marked, if any, signs of the supposed impending change. The suggestion of Mr. Shiras that "one can buy at half the cost [of shooting the animals] the skins or horns that later may adorn the home as a result of the huntingtrip " is most assuredly one that will not appeal to the present-day British sportsman.

Apart from all this, the author is to be heartily congratulated on the pictorial results of the three trips upon which the article before us is based. These three trips comprised one in April to an isolated coral-reef in the Bahama group tenanted by large breeding colonies of " manof-war birds" "and "boobies"; a second to New Brunswick in search of moose and deer, and later on to Newfoundland for caribou; and

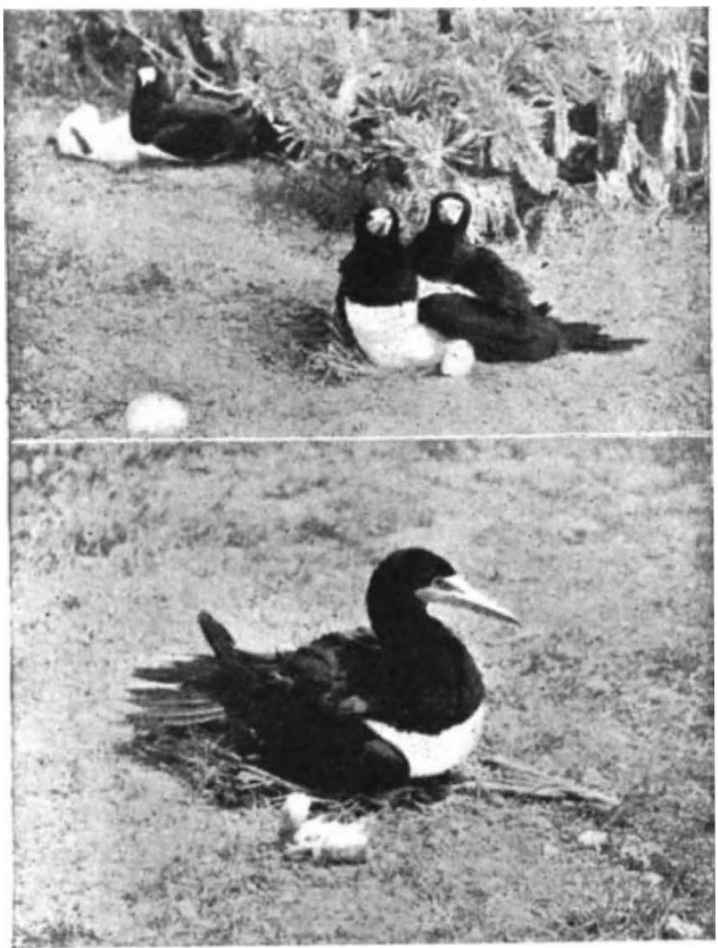

FIG. I.- "Boobies" protecting their young from the sun, and a single bird incubating. From the National Geographic Magazine.

a third to Florida for brown pelicans and other local birds. The majority of the photographs were obtained on Kay Verde, as the aforesaid coral-reef is called, and comprise some excellent pictures of the booby colony, together with individual boobies incubating (herewith reproduced), and of man-of-war birds on the wing as well as of their callow young. It appears that the former birds are compelled to protect their

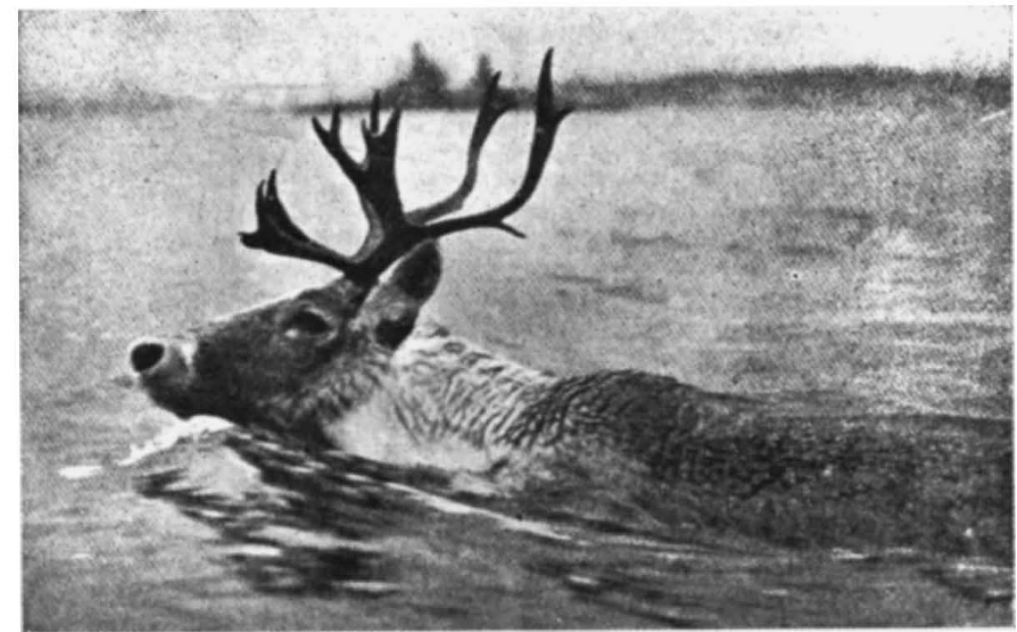

F1G. 2.-Caribou Stag with Symmetrical Horns. Photographed at a distance of 8 feet. From the National Geograpkic Magazine.

young from the fierce rays of the sun by brooding them with their wings. The photographs of flocks of pelicans on the wing come almost as a revelation, although in some instances the birds in the foreground are unavoidably more or less blurred. The picture of something like a thousand young pelicans disporting themselves at the water's edge is another calculated to make the bird-lover long for a glimpse of such a wondrous scene. Mr. Shiras was equally successful in " snap-shotting," either by flashlight or in daylight, moose in the forest and caribou swimming in the lakes, one of the pictures of the latter (Fig. 2) showing most admirably the white collar distinctive of full-grown stags.

\section{A CONTRIBUTION TO THE INDIGO QUESTION.'}

$A$ DECADE has elapsed since the chemical facA tories of Germany began to enter seriously into competition with plant indigo, and the gradual displacement of the latter by the synthetical product has from time to time been recorded in these columns. The writer of this notice was invited in 1900 to make known in this country the chemical history of this new development of applied science, and in a paper read before the Society of Arts the following year, after describing the various synthetical processes then available, attention was directed to the extraordinary want of skilled scientific supervision which had, down to that period, marked the cultivation of the plant and the processes of extraction carried on in India. In the year $1902 \mathrm{Mr}$. Bloxam was appointed to the research station of Dalsingh Serai, having associated with him Mr. H. M. Leake as biologist and $\mathrm{Mr}$. R. S. Finlow as assistant chemist. Work was carried on in India by this staff until the spring of I904, when Messrs. Bloxam and Leake returned to England.

1 Report to the Government of India, containing an Account of the Research Work on Indigo performed in the University of Leeds, I905-7. By W. Popplewell Bloxam, with the assistance of S. H. Wood, I. $Q$ Orchardson, R. Gaunt, and F. Thomas; and under the general supervision of Mr. A. G. Perkin, F.R.S, of the University of l.eeds. (Published by Order of His Majesty's Secretary of State for India in Council.) 